\title{
Docteur Jekyll \& Mister Hyde de Mattotti-Kramsky, el quiebre del verosímil
}

ABSTRACT: This article analyses the comic book Docteur Jekyll \& Mister Hyde by Mattotti-Kramsky, adaptation of the novel written by Robert L. Stevenson, The Strange Case of Dr Jekyll and Mr Hyde. Relying on the notions of adaptation, transposition and intertextuality, the conclusion is reached that adaptation involves a specific gaze regarding the source-text, which shows a distinctive reading and the adoption of a number of decisions in the production instance. The tension between the virtual and the actual, and the updating of reading, allows approaching the comic book from two main perspectives: the narrative one, located in the continuum of the sequence, and the non-figurative one, consisting in denarrativating the image (abstract comics and Figural image, Gilles Deleuze).

Keywords: transposition, comic, intertextuality, image.

RESUMEN: En este artículo se analiza la historieta Docteur Jekyll \& Mister Hyde firmada por Mattotti-Kramsky, adaptación de la novela de Robert L. Stevenson, The strange case of Dr Jekyll and Mr Hyde. Seguido al examen de las nociones de adaptación, transposición e intertextualidad, se concluye que la adaptación implica una mirada sobre el texto-fuente que evidencia una lectura distintiva, así como un cierto número de decisiones en la instancia de producción. La tensión entre lo virtual y lo actual y la actualización de la lectura permite el abordaje de dos ejes principales en la historieta: el narrativo, situado en el continuum de la secuencia y el no figurativo que retoma la operación que consiste a desnarrativizar la imagen (historieta abstracta e imagen figural, Gilles Deleuze).

Palabras clave: transposición, historieta, intertextualidad, imagen. 


\section{Introducción}

Docteur Jekyll \& Mister Hyde, firmado por Mattotti-Kramsky y publicado por Casterman (Francia) en 2002, es una adaptación del clásico literario de Robert L. Stevenson The strange case of Dr Jekyll and Mr Hyde.

Esta adaptación encuentra en principio dos problemáticas generales: la asociada a la transposición entre literatura e historieta y la noción general de intertextualidad, de diálogos entre dispositivos. En el pasaje entre dispositivos, se producen cambios fundamentales que se atribuyen a la configuración específica de cada uno, sus elementos constitutivos y sus vínculos con el público. La adaptación implica una mirada sobre el texto-fuente que evidencia una lectura distintiva, así como un cierto número de decisiones en la instancia de producción. Estos aspectos se materializan en las estrategias visuales propias a la historieta y se vinculan al estilo particular, el gesto de los autores (dibujante y guionista). La tensión entre lo virtual y lo actual y la actualización de la lectura, permite un abordaje complementario al de las cualidades narrativas, fundadas en el continuum de la secuencia: aquel de un examen no figurativo de la imagen-historieta.

El primer eje de análisis a desarrollar, se basa en el trabajo comparado entre relato literario y relato-historieta, centrado en el découpage y en el vínculo escripto-icónico. El segundo eje, aborda la operación que consiste a desnarrativizar la imagen. El apoyo en la reflexión sobre la posibilidad de la historieta abstracta, se complementa con la distinción entre la figuración narrativa y lo figural no narrativo que Gilles Deleuze aplica a la pintura de Francis Bacon, donde el alejamiento de la figuración (como representación) se halla bien manifiesto. El filósofo explicita dos modos posibles de escapar a la figuración, a saber, por la abstracción, la forma pura y lo figural, por abstracción y aislamiento, donde las figuras se presentan sin vinculo mutuo; ellas actualizan a través de una serie de vectores encontrados, las fuerzas de los cuerpos.

Las dos instancias - narrativa y no figurativa- no se excluyen mutuamente en el seno de una misma obra y nos equivocaríamos -aún para el caso de la adaptación de la literatura- al valorizar exclusivamente el eje literario y escritural de la narración.

\section{Algunas consideraciones sobre la operación de adaptación}

La teoría de la adaptación incluye una línea de estudios que establecen la noción de fidelidad como válida en los trabajos comparados. Esta visión de la lealtad de una adaptación respecto de su texto fuente es errónea y conduce a pensar que ser segundo o posterior implica inferioridad respecto de lo que precede, cuando este no es necesariamente original ni autoridad. La adaptación 
implica una lectura activa y situada, en un momento histórico y cultural específico. En la transposición se pasa de un lenguaje a otro, de una época a otra, de una lengua a otra. Examinando comparativamente las dos extremidades de la transición vemos cómo la historieta propone una mirada compleja sobre el texto y una recreación. La historieta que analizamos no es una adaptación de una historia ya narrada, sino una construcción activa de un nuevo sentido que ubica al referente literario únicamente como punto de partida o antecedente. La noción de transposición (Steimberg, 2005) abre el juego de la teoría adaptativa y analiza los vínculos entre discursos como dinámicos y mutuos y siempre situados en un estilo de época: «La mirada del texto fuente de cada una de las transposiciones literarias que vemos en el cine, o que leemos en historieta, suele oscilar entre el privilegio del tema, con su carga de motivos asentados prioritariamente en el relato, por un lado, y el del resto de sus rasgos retóricos, con sus huellas de estilo individual y de época, por otro (Steimberg, 2005: 98).

Al tratarse Docteur Jekyll \& Mister Hyde de una adaptación de un clásico de la literatura universal, podemos pensar que el lector conoce el texto de referencia y, a su vez, otras adaptaciones existentes del mismo (a cine, teatro, etc.). Linda Hutcheon afirma que el lector se habitúa a ver la adaptación en sí misma, es decir, teniendo en cuenta que se trata de una obra ligada a otras que la preceden. La experiencia de vivir las adaptaciones como adaptaciones -Adaptations as Adaptations (Hutcheon, 2006: 8)-, conscientes de ese palimpsesto de repetición y variación, permite pensar la adaptación como un proceso y no como un producto, como la migración de relatos e ideas y sus correspondientes relecturas. La especulación sobre la postura del lector/espectador no nos ocupa en este trabajo; sin embargo, no sería en vano referir a la visión de Jan Baetens que en este sentido permite pensar las adaptaciones como obras autónomas. Este autor afirmó en su charla «Adaptation comme construction de soi» (coloquio Bande dessinée et adaptation: du texte aux images, Universidad de Bourgogne, Dijon, febrero de 2012) que la pérdida de jerarquía de unas formas expresivas con respecto a otras (como por ejemplo la literatura respecto de la historieta) se acompaña a su vez, de una erosión de la atención puesta sobre la transmedialidad. El lector ya no va a la fuente a la hora de leer una adaptación, e incluso desconoce parcial o completamente los medios, géneros y relatos que la precedieron.

En la adaptación literatura-historieta, se produce un pasaje de un lenguaje que narra a otro que narra y muestra simultáneamente. A propósito de esta cuestión, Linda Hutcheon enumera lo que ella considera como los tres modos de vinculación -modes of engagement (Hutcheon, 2006: 22)- entre espectador/lector y el medio: en primer lugar, telling (decir, contar); luego showing (mostrar); y por ultimo interacting (interactuar). La historieta se sitúa en los límites entre el primer y el segundo modo de vinculación, la adaptación teniendo aspectos que la acercan a su referente literario y otros que suscitan un análisis autónomo. Thierry 
Groensteen afirma que la historieta - a diferencia de la literatura que se sirve de la descripción verbal- se apoya en la mostración. El concepto retomado de André Gaudreault, se centra en la función mostrativa de las imágenes: mostrar en vez de decir (Gaudreault, 1999). La mostración es una descripción virtual que se cumple mediando la participación del lector. Se somete teóricamente la imagen a dos lecturas: una descriptiva, donde la viñeta se aísla para obtener un repertorio de lo que ella presenta, y la otra, narrativa, donde se selecciona únicamente los elementos que participan de la cadena de eventos funcionales a la dinámica del relato (elementos constantes y elementos contingentes).

La teoría de la mostración en historieta se vincula a su especificidad enunciativa, que marca una cualidad propia del dispositivo. Gaudreault, se refiere al rol asumido por el narrador fundamental de la literatura traspasado al teatro y propone la noción de mostrador: no existe una consciencia intermediaria que presente el espacio y la acción (como lo hace el lenguaje en la literatura), estos se presentan a sí mismos. La mostración, afirma Groensteen, se asocia a la representación icónica de un objeto y permite una apropiación global, sintética e inmediata (Groensteen, 1991).

La contingencia del proceso de metamorfosis en la adaptación, suscita en su estudio una orientación hacia especificidad del lenguaje de la historieta. En general, el análisis comparado de los medios en el contexto de la transposición y la intertextualidad permite caracterizar a cada uno de ellos. Thierry Groensteen (Groensteen, 1998) establece el vínculo entre adaptación y especificidad de las artes. Siendo que cada una de ellas ofrece criterios materiales y formales que le son propios, el autor retoma una discusión célebre que tienen sus primeras voces en Gotthold Ephraim Lessing, quien en El Laoconte (1766) refuta la idea de la equivalencia de las artes, específicamente pintura-poesía (ut pictura poesis).

El relato es redefinido en su encarnación mediática (Gaudreault, 1998: 32), por lo que podemos hablar de una recreación adaptativa; «cuerpo a cuerpo» entre la idea (fábula) y el material (media). Groensteen vincula el auge de la práctica de la adaptación con el fenómeno de reproductibilidad técnica de la modernidad, buscando sus orígenes en las transformaciones en los campos de la cultura y el arte del siglo XIX: los progresos técnicos, la reproducción y multiplicación de textos e imágenes, la consagración del relato bajo la forma de la novela-que desplazó a la poesía-, el aumento de público para la ficción, etc. Este proceso permitió al relato -donde la idea y el material son ya indiscernibles- volverse un objeto móvil. En general, ha prevalecido en las adaptaciones (cuyo origen es la literatura) la preminencia de la historia, acentuándose el desarrollo ficcional y ocultándose el trabajo de los medios expresivos (pretensión de transparencia). Solo algunas adaptaciones, como la que analizamos aquí, se centran en la redefinición del sujeto o fábula a partir de los criterios materiales propios a su arte. 


\section{La metamorfosis en clave visual}

Es atributo de cierta historieta contemporánea el explotar los recursos visuales e historietísticos en pos de establecer referencias múltiples, entre otras, hacia el propio autor y su estilo, el gesto enunciador. La expresión de ideas y sensaciones provocadas por las obras, pueden pensarse fuera de lo estrictamente narrativo, como veremos más adelante.

Les elementos plásticos como la línea, el color y la luz no funcionan únicamente al servicio del relato, sino que evocan a su vez ideas-imágenes ligadas a puras sensaciones y la no figuración. El hilo conductor del álbum es la deformación o devenir informe del personaje, que Mattotti hace imagen a través del tratamiento de los cuerpos y el cromatismo. La línea de contorno coloreada, la saturación cromática, los contrastes simultáneos, el claroscuro y los gradientes, el realce de texturas propias a los materiales (pastel sobre papel), evidencian la riqueza plástica y gráfica de Docteur Jekyll \& Mister Hyde.

En el trazo de Mattotti, el personaje principal se tuerce y se desmaterializa por la mancha. Esta pérdida de forma se sublima a través de los blandos, plásticos y flexibles cuerpos mattottianos. Estos son impulsados por un vector único que los eyecta y los proyecta; siguen direcciones acentuadas por movimientos unitarios. Por ejemplo, en la plancha 48 (viñeta 3), vemos el cuerpo de Hyde apoyado sobre una superficie horizontal, en un bar. Este se extiende hacia otra figura humana, ofreciéndole un sobre con el brazo estirado. Todo el cuerpo se dirige hacia una única dirección y la cabeza deviene una suerte de flecha. El mentón acentúa su punta hasta el extremo. Para reforzar esta tensión, no hay rostro, solo una distribución de sombra y luz en gradiente. En la plancha siguiente, en la tercera viñeta, el cuerpo es una masa homogénea, un pleno plano negro. Del mismo modo, toda la fuerza lo dirige en una única dirección y el rostro describe una tensión; de la sombra emergen sus trazos: ojos, boca y nariz. En la primera viñeta de la plancha 52, el cuerpo se encuentra corriendo. Se evoca una vez más la flecha: todo el movimiento es contenido en una curva. Este tratamiento para el cuerpo de Hyde recrea una serie de movimientos espasmódicos, siempre en tensión; a cada espasmo hay un cambio, una modificación de la forma [ver figura 1 en anexo].

Los climas cromáticos construidos para cada secuencia son muy ricos y variados. Cada plancha posee una distribución cromática particular, una muy diferente de la otra. La línea y el tratamiento de superficie también varían consistentemente. En ocasiones el trazo se encuentra bien presente, prevaleciendo la cualidad dibujística de la imagen (a la manera de Otto Dix o George Grosz), y en otras, los gradientes y las superficies de color acercan la imagen a lo pictórico (referencias al fauvismo, el color bestial). Por otra parte, las perspectivas forzadas y la construcción del espacio evocan los escenarios del film expresionista alemán 
Das Cabinet des Doktor Caligari (Robert Wiene, 1920). Por ejemplo, la secuencia de la plancha 13, muestra al doctor Jekyll consagrado al trabajo científico en su laboratorio. La presencia simultánea de colores saturados como el amarillo, rojo y violeta y algunas sombras de gris cromático, crean una atmósfera dinámica y corroboran la intensidad de la situación. Los elementos del fondo se caracterizan por los plenos planos cálidos, mientras que el personaje porta los fríos. La viñeta 3 ilustra esta distribución (figura 2), donde la repartición cromática aporta un recorrido visual bien pregnante: las zonas de sombra a los lados de la imagen y el personaje a contra luz se forman de diferentes grados de violeta y las zonas de luz de rojos y amarillos. Opuestamente y constituyendo una forma de monocromía, la plancha 28 se aleja de los contrastes mayores de color. Vemos sombras y luces en diferentes niveles de saturación al tono (gris) y la fuerte presencia de una luz amarillo-verdosa que suscita una atmósfera extraña y oscura. Asimismo, la presencia de blanco sobre la superficie cromática es remarcable en la plancha 31. El gris y blanco cromáticos conforman grandes plenos y se combinan con colores vivos como el amarillo y otros menos saturados como un verde claro y naranja oscuro. Esta yuxtaposición de cromático y acromático y los espacios vacíos (sola presencia del personaje) provocan una suerte de ambiente metafísico evocando los paisajes de Giorgio De Chirico.

\section{El enigma abortado, la secuencia}

El tema fundamental de esta novela escrita por Robert Louis Stevenson y publicada en 1886, es la doble faceta cuerpo/espíritu en la vida del doctor Jekyll y su transformación.

La confrontación del relato literario y su configuración en historieta, permite desarrollar el eje de análisis narrativo. La imagen de historieta narrativa implica dos macro-dimensiones que contribuyen a la economía del relato: la distribución secuencial de las viñetas y el contenido de las imágenes individualmente. Como afirma Jean-Louis Tilleuil a propósito de la imagen narrativa, lo icónico propone -como lo escritural- indicaciones relativas al tiempo y espacio a través de la presencia o ausencia de personajes, el encuadre, punto de vista, variaciones de tamaños, escala, etc., que intervienen también en la construcción/reconstrucción de la narración por el lector (Tilleuil, 1991). Thierry Groensteen explica a propósito el proceso de lectura narrativa, donde el lector discrimina en cada cuadro los elementos constantes y los elementos nuevos para seguir la historia. Este tipo de lectura es funcional al desarrollo de la narración, permitiendo reconstruir el relato.

En la historieta que analizamos, uno de los primeros puntos a definir respecto del relato literario, es el modo de dirigir la intriga. En la novela la historia 
es construida a partir de la persistencia del enigma: la clave del misterio no se manifiesta sino hasta el fin del relato. Las imágenes invierten esta estructura y el lector conoce desde el principio el origen de la intriga, que de este modo se anula.

El trenzado texto-imagen en la secuencia (la voz de Jekyll por el texto y aquello que muestran las imágenes) establece al menos dos tiempos presentes en la narración: el del momento en que el doctor escribe su carta y el del momento en que los acontecimientos se desarrollan en la imagen, reportados a su vez por las palabras del doctor. Esos dos tiempos se funden mutuamente en la última plancha en que Jekyll-Hyde mueren y el tiempo de la imagen y el del texto se encuentran (como Jekyll esta muerto, el narrador omnisciente toma el relevo).

Las onomatopeyas, asociadas por su definición a las cualidades visuales y auditivas de las palabras, como una puesta en escena plástica del texto, están presentes en ciertas secuencias y se integran dinámicamente en la imagen. Su forma densa y voluminosa puede apreciarse en la plancha 13: a través de un plano picado, vemos la totalidad de una habitación y en el interior en el suelo, el cuerpo retorcido del personaje principal, de un tamaño miniaturizado. La onomatopeya evoca el dolor y el malestar del personaje; las letras emanan de su cuerpo y atraviesan el espacio verticalmente. Ellas adquieren volumen, sus cuerpos se proyectan hacia la superficie. En la plancha 24, la onomatopeya opera también una suerte de proyección, llevando el grito de dolor y de angustia una vez más. Las letras salen por la ventana y marcan un gran contraste de blanco sobre negro y rojo, entre el calor y la agitación del interior y la neutralidad del exterior [ver figura 3].

La primera secuencia se consagra a presentar a Hyde en su deambulación urbana. La primera plancha del álbum (figura 4) devela ya su presencia oscura, bajo la forma de una sombra citadina que se proyecta sobre los edificios, el tranvía, la calle. Se trata de una figura elíptica, en el borde entre lo cromático y lo acromático, en movimiento que determina un recorrido visual en la superficie de la plancha siguiendo un movimiento serpenteante, de curva y contra-curva. El texto se apoya en los cartuchos y expresa las palabras de Jekyll, su arrepentimiento y su lazo con su lado cruel e innoble. Como dijimos, se opera una inversión de la estructura narrativa, en la medida en que la historieta nos muestra desde el comienzo la parte luciferina del doctor bajo la forma de Hyde. Las planchas siguientes se centran en la mostración de su maldad, en el evento en que pisotea y ataca a una niña sin razón aparente. En la novela es el evento que provoca la inquietud de Utterson, cuyo rol es el de revelar la intriga. El misterio, vehiculizado por la presencia furtiva de Hyde y los cambios de humor y de salud de Jekyll, se sostiene hasta el desenlace en que muere dejando una carta de confesión. La historieta revela este enigma y construye la secuencia de la visita 
de Utterson a la casa de Jekyll y la lectura de la carta, seguido a la mostración de Hyde (primera secuencia). En consecuencia, la historia se centra en Hyde y su deseo, construyendo de forma alternada escenas de la vida de Jekyll ligadas directamente con la búsqueda de su droga y su malestar frente a la vida en sociedad. El trenzado entre las planchas 8 y 9 (figura 5), determina una secuencia fundamental de la historieta y marca la fusión simbólica y física de los personajes; en los ojos de Hyde vemos el cuerpo de Jekyll. A través de la sucesión de viñetas, las figuras-cuerpos se apoyan sobre una misma curva. El plano se cierra cuadro tras cuadro hacia el ojo de Hyde que fija su mirada en un punto único. El rostro se estructura en tres curvas, y describe una expresión de odio y hastío: los dientes, breves trazos blancos, y los ojos, entrecerrados. El cuerpo es una masa oscura, límite entre lo cromático y lo acromático, un color neutro despojado de vida, un gris revestido de un cromatismo inquietante.

La confrontación de la cultura y lo salvaje es muy clara en la novela y se reproduce y se exalta en la historieta. El elemento de la dualidad y la crueldad de Hyde es intensamente tematizado por las imágenes: la distinción entre el bien y el mal, la psiquis entre el consciente-inconsciente. Se pone el acento en los deseos de Jekyll a través de Hyde. ¿Cómo dar rienda suelta al deseo escindiéndolo del control de la conciencia y llevarlo al acto? Hyde lleva a cabo una cantidad de acciones ligadas a la pulsión sexual y la violencia: ataca a la niña, agrede a personas en la calle, comete asesinatos y relaciones sexuales violentas con prostitutas, asesina a una mujer y a su amigo Lanyon. La materialización de la pulsión mas allá de toda restricción (del orden de la internalización de las reglas sociales) es asumida por la bestia que no posee control sobre sí o autoconciencia. La bestia también aparece en el trazo del dibujante y su retórica de la mancha, la línea brusca, el color intenso y saturado. La animalidad es asumida por la figura de Hyde y también otros personajes que pertenecen a su mundo. El animal es dos veces evocado: en la falta de autoconciencia y en el físico brutal. Gilles Deleuze (2002: 27) refiriendo al devenir animal de los sujetos y específicamente para el caso de la pintura de Bacon afirma:

Les déformations par lesquelles le corps passe, sont aussi les traits animaux de la tête. Il ne s'agit nullement d'une correspondance entre formes animales et formes de visage. En effet, le visage a perdu sa forme en subissant les opérations de nettoyage et brossage qui désorganisent et font surgir à sa place une tête. Et les marques ou traits d'animalité ne sont pas d'avantage des formes animales, mais plutôt des esprits qui hantent les parties nettoyées... Nettoyage et traits comme procédés de Bacon, trouvent ici un sens particulier. Il arrive que la tête d'un homme soit remplacée par un animal; mais ce n'est pas l'animal que comme forme, c'est l'animal comme trait [...] Au lieu de correspondances formelles, ce que la peinture de Bacon constitue, c'est une zone d'indiscernabilité, d'indécidabilité, entre l'homme et l'animal. L'homme devient animal, mais il ne devient pas sans que 
l'animal en même temps ne devienne esprit, esprit de l'homme [...] Ce n'est jamais combinaison de formes, c'est plutôt le fait commun: le fait commun de l'homme et de l'animal.

El punto de encuentro entre el hombre y el animal es la carne, ese hecho común descrito por Deleuze está presente en las figuras baconianas y es aplicable a las formas de Mattotti, donde los trazos animales y bestiales emergen del borrado de la materia en la superficie de la imagen.

La novela se refiere a Hyde (salvo por algunas excepciones) en segundo grado, son las palabras de los personajes que reportan a las acciones del malvado. Contrariamente, la tendencia en la historieta es mostrar a Hyde en primer grado: el lector es testigo directo de sus acciones en imágenes. El misterio deja su lugar a la mostración, y la intriga es anulada doblemente: el lector ve a Hyde en todas sus acciones y a su vez, lo ve desde un principio.

\section{5. ¿Desnarrativizar la historieta?}

La tensión entre lo virtual y lo actual al seno de la viñeta, así como la distinción entre descriptivo/narrativo, permiten centrarse en un análisis -mas allá de lo narrativo- de la virtud plástica de la historieta. Es necesario para comenzar, aislar deliberadamente ciertas planchas y viñetas susceptibles de entrar en un juego de fuerzas que sobrepasan lo estrictamente figurativo y que quiebran el verosímil.

Una lectura no narrativa es posible y es la menos habitual, ya que la historieta se lee generalmente como una historia contada (la coherencia narrativa es un postulado, cuando esta falta, el horizonte de expectativas del lector es sobrepasado y puede darse una ruptura del contrato de lectura). Sin embargo, existen algunas historietas donde esa dimensión desnarrativizadora es fuerte, especialmente en la denominada historieta abstracta.

La actualización de la narración o descripción virtuales puede producirse sin un orden prefigurado. Harry Morgan (2003: 34), afirma que a pesar de la narratividad intrínseca del dispositivo historietísico, el lector puede detenerse en las cualidades visuales de la imagen.

Toute lecture, quel qu'elle soit, dégage le récit. Mais on peut aussi se contenter de regarder le dessin -puisqu'il offre un simulacre de la nature- et jouir de la sorte des plaisirs de la figuration. La lecture peut se faire à l'intérieur d'une seule vignette ou, à l'inverse, procéder du tressage, c'est-à-dire de la réunion d'images et de fragments d'images éloignés. Elle peut enfin résulter d'un parcours non-linéaire, voire d'une prise de connaissance globale du matériau iconique. 
Thierry Groensteen retoma la discusión sobre la posibilidad de una historieta abstracta y la cuestión de su vínculo con una definición extensa y conveniente del dispositivo, como secuencial, múltiple, visual, narrativo, etc. La historieta abstracta es un fenómeno contemporáneo, ligado a la experimentación y el falseo de las fronteras predefinidas. El autor se pregunta si las historietas pueden definirse como tales una vez que salen de la esfera de la mimesis, ya que una parte fundamental de la definición, a su criterio, es el ser narrativa (Groensteen, 2011). El contenido de las imágenes abstractas en la historieta se compone de elementos plásticos y las relaciones que se establecen entre ellos. En los casos en que no hay lazos de causalidad, Groensteen propone hablar de «serie» más que de «secuencia», ya que esta implica un orden lógico. La idea de serie puede ser fructífera para un examen las sucesiones caprichosas de viñetas/imágenes donde no hay orden lógico o causalidad aparentes. Eso permitiría pensar en una historieta, como es el caso de Dr. Jekyll \& Mister Hyde, que se aleja de la figuración temporariamente, constituyendo series donde la cualidad de la imagen pura asciende y se pierde el vínculo con el verosímil. La historieta por su estructura previa, no podría definirse íntegramente como abstracta pero puede dar lugar en su interior a escapadas abstractas; por ejemplo, zonas en que se produce una serie de imágenes en lugar de una secuencia. En este sentido, Groensteen vuelve a la discusión sobre una definición de la historieta. La presencia de una plancha abstracta reafirmaría la cuestión de que su estructura espacio-temporal es preponderante para la elaboración de una definición amplia, independientemente de toda condición relativa a la figuración o la narración: «[...] cet appareil, ce dispositif, suffit à établir l'appartenance de l'œuvre au champ de la bande dessinée, en toute logique, le dispositif doit dès lors être reconnu comme constituant l'élément central de la définition de la bande desciñe» (Groensteen, 2011: 13).

La historieta abstracta constituye una parte ínfima de la producción historietística contemporánea pero alcanza para cuestionar una vez mas su definición (del mismo modo que otras evoluciones contemporáneas del medio, como lo digital) y otorgar por ejemplo, «vacaciones a la figuración», afirma Groensteen (2011):

La bande dessinée abstraite ne représente pas statistiquement qu'une partie infime de la production mais son poids symbolique est considérable puisqu'elle invite à reconnaitre que la bande dessinée peut donner congé à la narration, à la figuration, sans cesser d'être de la bande dessinée; dans le même temps la bande dessinée numérique, phénomène en devenir et dès présent beaucoup plus massif, a son côté, donné congé au papier. Face à ses évolutions que reste-t-il des définitions traditionnelles de la bande dessinée? Rien d'autre que le partage d'inscription ou affichage, en un mot le dispositif, la «pluralité d'images solidaires. 
La historieta abstracta nos obligaría a suprimir de una definición amplia la cuestión de la narración, del mismo modo que la historieta digital obligaría a dejar de lado la cuestión del soporte-papel, el libro o la prensa. La noción de «solidaridad icónica» (Gorensteen, 1999) es un principio fundador y principal criterio para una definición extensa de la historieta y excluye la cuestión de la narración. Estas imágenes solidarias participan de una sucesión y si bien están separadas unas de otras, se determinan por su coexistencia. A su vez esta coexistencia debe responder a algún tipo de correlación.

Gilles Deleuze en L'image-temps. Cinéma 2, propone la distinción entre dos regímenes de la imagen (cinematográfica), a saber, el orgánico y el cristalino. Ambos pueden aplicarse tanto a la descripción como a la narración. Por un lado, la descripción orgánica (o cinética) utiliza los parámetros sociales del sujeto definido, identidades personales, referencias (acciones, etc.). La descripción se centra en el acto y define situaciones sensorio-motoras y relaciones lógicas. Se trata de la imagen-acción ligada al cine realista. Por otra parte, la descripción cristalina (o cronológica), ella vale por su objeto, y lo constituye, crea otras descripciones que lo contradicen y lo desplazan. Esta descripción crea un objeto descompuesto y multiplicado, su propio objeto, creando situaciones ópticas y sonoras -sensoriales-, centradas en la visión (y no el acto). La distinción entre lo sensorio-motriz y la visión opera el desplazamiento de la acción y el movimiento a la videncia. El hombre pasa del acto a la visión del mundo y opone una al otro (Sauvagnargues, 2005: 245):

Avec l'image-cristal, la polarité du virtuel et de l'actuel prend la réalité d'une oscillation permanente, de sorte que le privilège du virtuel s'évanouit : l'image-cristal est un consolidé de virtuel et actuel, et le virtuel comme tel s'avère entièrement dépendant de l'actuel. [...] Avec l'image-temps l'objet actuel se dissout sans doute dans son processus d'individualisation, mais la présence physique de l'image indique aussi que tout virtuel exprime aussi sa voie d'actualisation.

La narratividad producida por el encadenamiento de las imágenes es una actualización operada por el lector. Lo no-narrativo, por lo tanto, se halla siempre presente en la virtualidad o en esa tensión entre virtual y actual. A pesar de la lectura secuencial de la imagen historieta, que la acerca a su función narrativa, en el aislamiento de una imagen el ojo del lector la recorre y se detiene en uno o varios detalles, de forma aleatoria o errática, contrariamente a la descripción literaria, donde debe respetar un orden y un tiempo determinados por la linealidad del discurso. En la imagen, uno puede detenerse en un punto específico y quedarse indefinidamente. La figura provoca un shock en el espectador, una sensación violenta que caracteriza la obra figural, opuesta a la visión orgánica que, me- 
diando la forma, provoca una respuesta sensorio-motriz (imagen convenida, fija y generalizada).

Gilles Deleuze propone una semiótica desligada de la significación y el discurso: una aproximación a las imágenes que estimulan el pensamiento y que no se explican por su significación discursiva. Se trata de imágenes complejas, sensaciones no reductibles a una significación discursiva pero que no dejan por ello de estimular el pensamiento. El pasaje de la «lógica del sentido» a la «lógica de la sensación» permite abordar las imágenes en que se opera un alejamiento del verosímil y donde la narración se anula de algún modo, siguiendo la dirección hacia una abstracción de formas y espacios o lo puramente figural (noción que explicaremos mas adelante). La abstracción se traduce por una disolución de formas, como puede verse hacia el fin de la obra, en la plancha 61 (figura 6), donde el personaje deviene progresivamente una mancha. Le deformación in crescendo se produce a lo largo las cinco viñetas en que el cuerpo -torcido y amorfo- es aún reconocible. En la primera imagen, el cuerpo se apoya sobre un eje sinuoso, donde identificamos algunas partes del rostro, los brazos atormentados, la mano en tensión, los dedos apuntando en diferentes direcciones. En las tres viñetas siguientes, la figura pierde sus cualidades de forma, cromatismo, densidad y es consumida; deglutida por el vacío negro. Nuestra hipótesis es que esta transformación informal del personaje encuentra los problemas analizados por Gilles Deleuze a propósito de la pintura de Francis Bacon. En su estudio Francis Bacon. Logique de la sensation, detalla los dos elementos pictóricos de las imágenes baconianas al interior del campo plástico. En primer lugar, la figura (forma humana, personaje); luego los plenos planos, zonas cromáticas; y finalmente, el lugar, los trazos que sitúan la figura. En esas circunstancias la forma del puro figural (por extracción o aislamiento) sobrepasa el carácter ilustrativo de la representación que relaciona siempre la forma con un objeto como referente y a otras formas. El aislamiento sería la respuesta de la no-figuración, la liberación de la figura. Por otra parte, en los casos en que no hay aislamiento de una única figura sino varias de ellas, la anulación de la narración se produciría seguido a un tipo especial de vínculo entre las figuras, a saber, aquello que Deleuze llama matter of fact, el cual no implica relaciones entre ideas u objetos, sino co-presencia de figuras; un vínculo eventual entre las figuras es el acoplamiento. En el caso de las imágenes múltiples, específicamente los trípticos, el vínculo entre las partes separadas existe, pero este no es lógico ni narrativo. Una viñeta única ocupa el ancho de la plancha 41 (figura 7). Esta presenta en sentido horizontal una figura compuesta de dos cuerpos que flotan en un espacio compuesto de plenos de color puro y tintes acromáticos. Los dos cuerpos se hallan entrelazados, siguiendo curva y contracurva. La intensidad de los cuerpos hace las formas incontrolables y poderosas. Mattotti crea vínculos entre fuerzas, mas que dibujar formas, vuelve aquellas visibles para que el lector las capte. La figure, afirma 
Deleuze, es la «forme sensible rapporté à la sensation [...] elle agit le système nerveux qui est de la chair» (Deleuze, 2002: 37). La sensación entonces está unida al cuerpo, llevando el color y la forma. «[...] Bacon ne cesse pas de dire que la sensation, c'est ce qui se passe d'un "ordre" à un autre, d'un "niveau" à l'autre, d'un "domaine" à l'autre. C'est pourquoi la sensation est maîtresse de déformations, agent de déformation du corps» (Deleuze, 2002: 40).

La secuencia de la transformación, el devenir Hyde de Jekyll, se despliega a través de dos planchas, 14 y 15 . En la multiplicidad de imágenes yuxtapuestas, se da una progresión entre un cuerpo y el otro: el personaje vive el sufrimiento del cambio físico. Si aislamos la plancha observando las imágenes a partir de una descripción cristalina, no vemos los lazos de causalidad, sino una sucesión caprichosa de figuras, una serie de espasmos. La primera viñeta muestra un cuerpo fragmentado: las partes dispersas flotan en un espacio abstracto. Una gran diagonal ascendente determinada por un brazo divide la imagen en dos cuadrantes, otras diagonales ascendentes y descendentes dinamizan la composición. Por otra parte, el contraste cromático es mayor, apoyado en un juego de contrastes simultáneos. La última viñeta presenta una figura en tensión y torsión. En las viñetas de la plancha siguiente, se opera una sucesión de formas amorfas: el cuerpo, el rostro, las manos se tensionan y tuercen, sufren la deformación. Hay una dirección hacia la pérdida de figuración en pos de hacer emerger la sensación. Esos pasajes entre estados que aíslan las formas y los espasmos en cada imagen develan un cuerpo que quiere escapar de sí mismo; análogo a lo figural en Bacon, como afirma Deleuze (2002: 24):

Toute la série de spasmes chez Bacon, est de ce type, amour, vomissement, excrément, toujours le corps qui tente d'échapper par un de ses organes, pour rejoindre l'aplat, la structure matérielle. Bacon a souvent dit que dans le domaine des Figures, l'ombre avait autant de présence que le corps, mais l'ombre n'acquiert cette présence que parce qu'elle s'échappe du corps [...] Et le cri, le cri de Bacon, c'est l'opération par laquelle le corps tout entier s'échappe par la bouche.

La viñeta 1 de la segunda plancha presenta una sombra puntuda que apenas alcanzamos a identificar. Tenemos a su vez el efecto del cuerpo escapando por la boca, a través de los gritos intensos. En la viñeta 3 vemos la forma animal de la cual emana una cabeza-boca ondulante, que emite un grito rojo y brillante. La sensación es materializada por esa carne viva.

Uno de los aspectos de la transformación es aquel del acercamiento a la forma animal y a su vez la constitución de Hyde como bestia, bestia-hombre. Deleuze insiste sobre el hecho que el cuerpo es carne; esta materialidad es acaso la zona común entre el hombre y la bestia. 


\section{Referencias bibliográficas}

Deleuze, G. (2002): Francis Bacon, logique de la Sensation, Paris, Seuil.

- (1985): Cinéma. 2, L’image-temps, Paris, Éd. de Minuit, vol. 1.

A. Gaudreault; T. Groensteen (1998): La transécriture: pour une théorie de l'adaptation: littérature, cinéma, bande dessinée, théâtre, clip, Colloque de Cerisy, Québec, Nota bene y Centre international de la bande dessinée et l'image.

A. Gaudreault; P. Ricoeur (1999): Du littéraire au filmique: système du récit, Paris, Nota bene.

GravetT, P. (2005): Graphic Novels: Everything You Need to Know, London, Harper Design.

Groensteen, T. (1999): Le système de la bande dessinée, Paris, Presses universitaires de France.

- (2011): Bande dessinée et narration. Système de la bande dessinée 2, Paris, Presses universitaires de France.

- (1991): «Entre monstration et narration, une instance évanescente: la description», en Colloque international L'image BD = Het stripbeeld, Leuven, Centre belge de la bande dessinée.

GubERN, R. (1987): La mirada opulenta. Exploración de la iconosfera contemporánea, Barcelona, Gustavo Gili.

Hutcheon, L. (2006): A theory of adaptation, New York, Taylor \& Francis.

Lessing, G. E. (1984): Laocoon: An Essay on the Limits of Painting and Poetry, The Johns Hopkins University Press.

Masson, P. (1985): Lire la bande dessinée, Lyon, Presses universitaires de Lyon.

Metz, C. (2002): Le signifiant imaginaire: psychanalyse et cinéma, Paris, C. Bourgois, vol. 1.

Morgan, H. (2003): Principes de littératures dessinées, Angoulême, Editions de l'An 2.

REY A. (1978): Les spectres de la bande: essai sur la B. D., Paris, Éditions de Minuit, vol. 1.

Sauvagnargues A. (2005): Deleuze et l'art, Paris, Presses universitaires de France.

SteimberG, O. (2005): Semiótica de los medios masivos. El pasaje a los medios de los géneros populares, Buenos Aires, Atuel.

Stevenson, R. L. (2008): Dr Jekyll and Mr Hyde, Londres, Penguin.

Tilleuil, J. L.; C. Vanbraband; P. Marlet; T. Belche (1991): Lectures de la bande dessinée: théorie, méthode, applications, bibliographie, Louvainla-Neuve, Academia.

Traversa, O. (1986): «Carmen, la de las transposiciones», en Actas del Primer Congreso Nacional de Semiótica, La Plata. 


\section{Anexo}
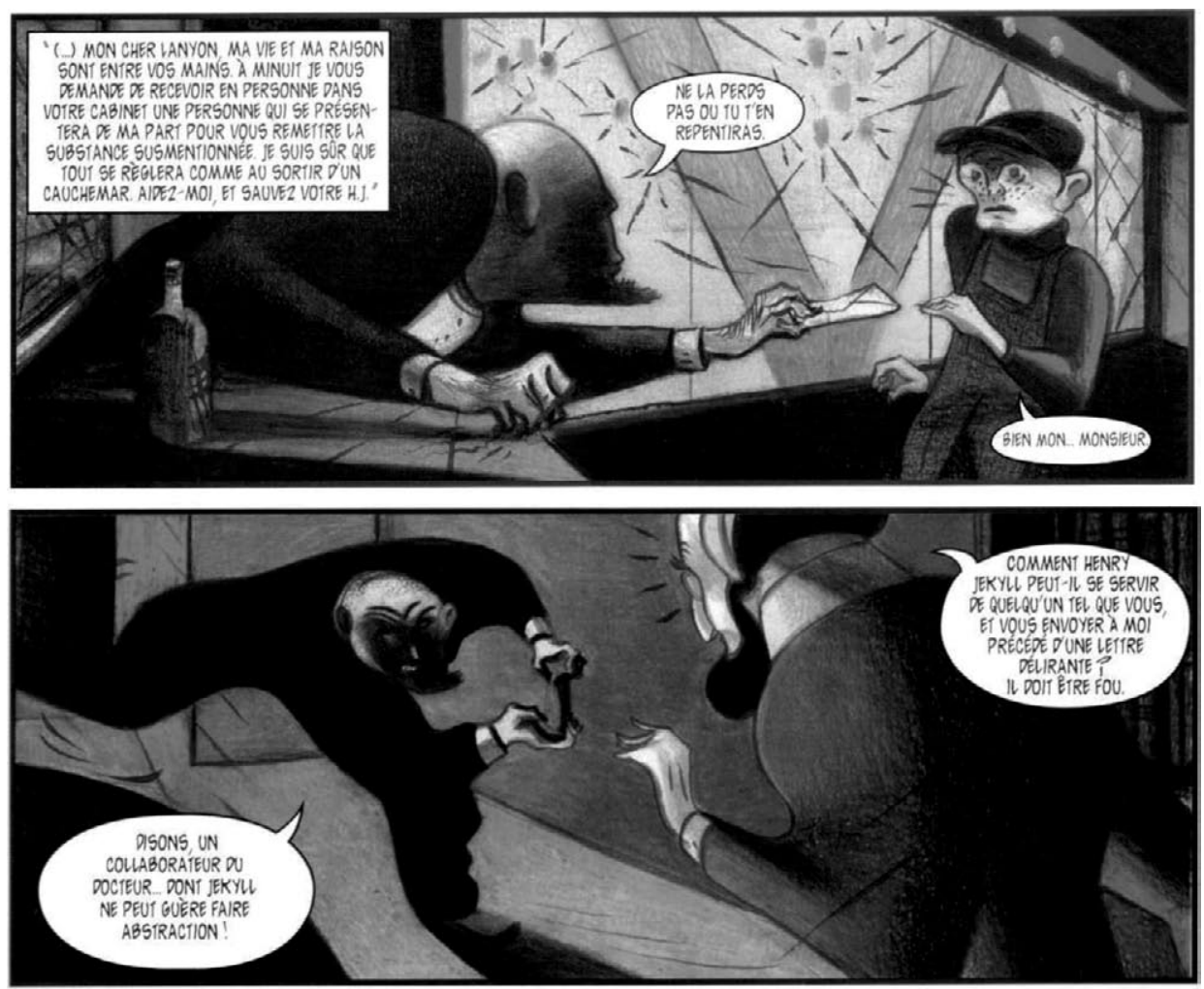

Figura 1

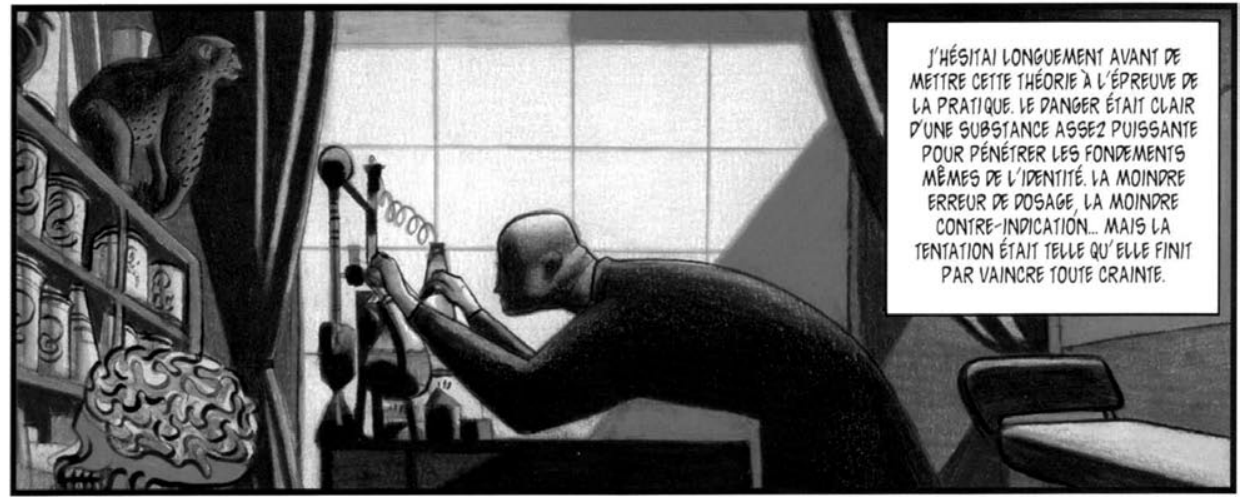

Figura 2 

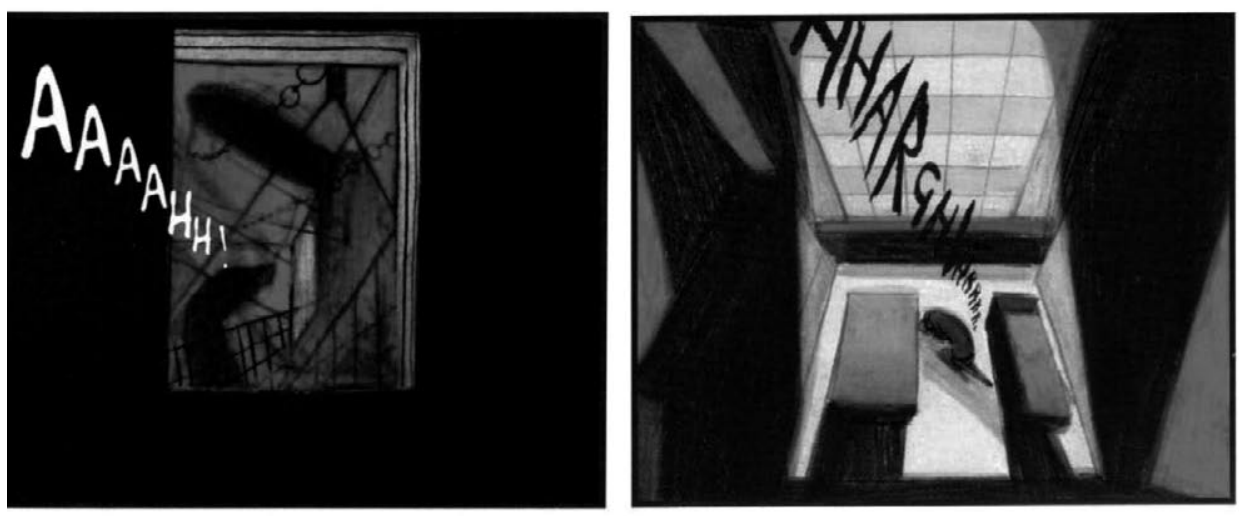

Figura 3

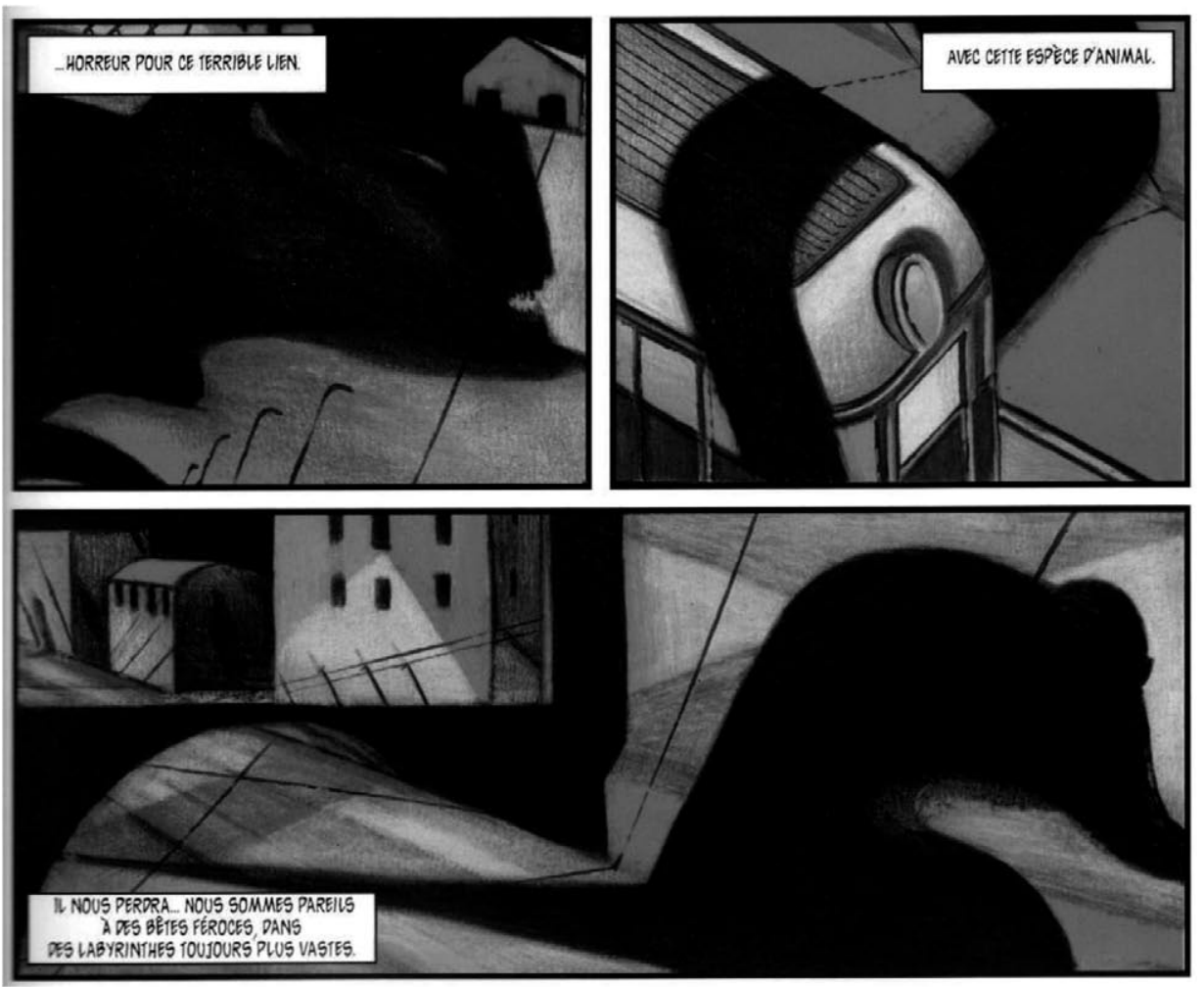

Figura 4 

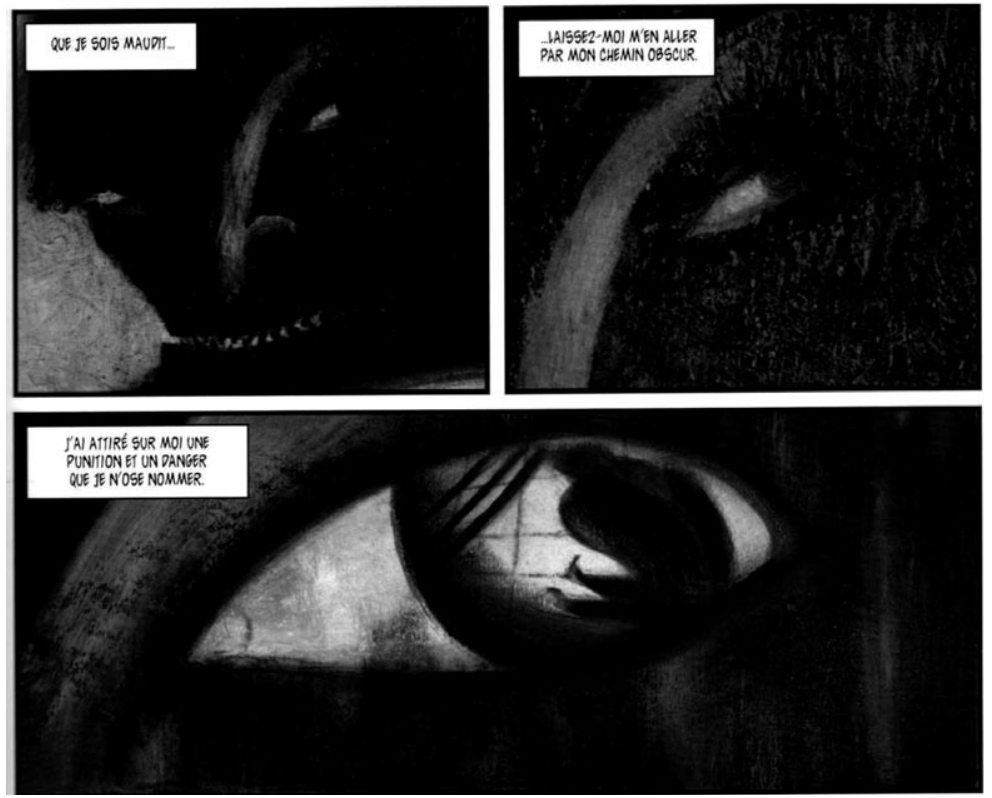

Figura 5

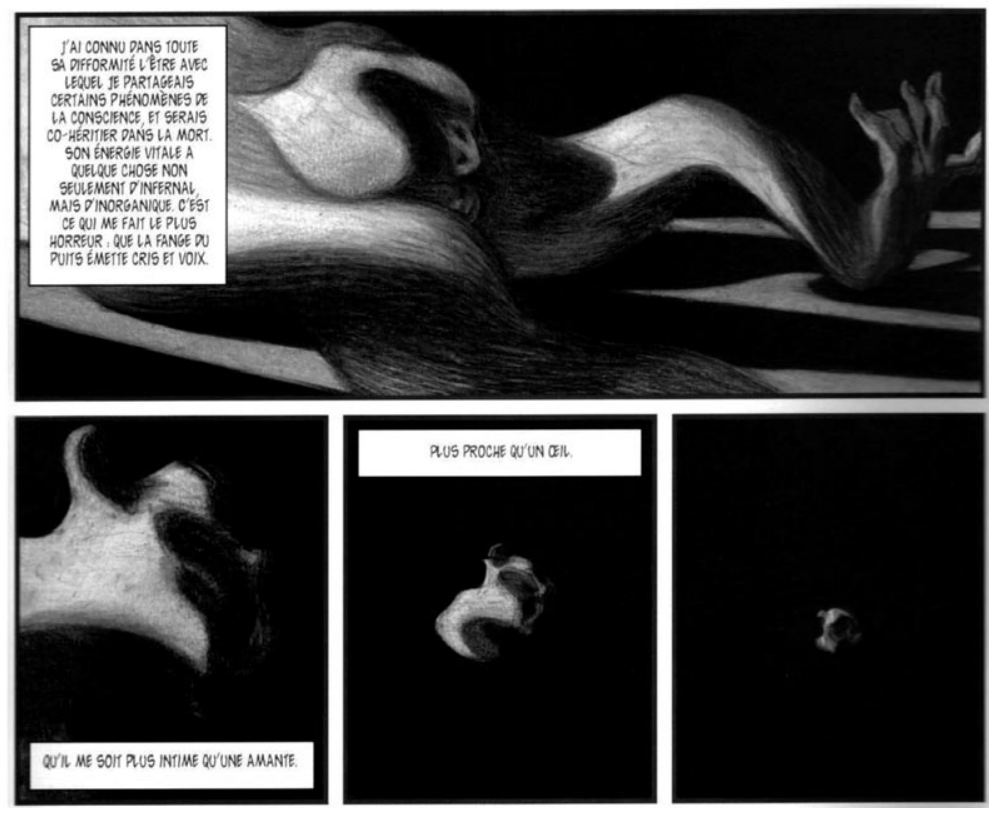

Figura 6 
64 CLR - DOI: HTTP://DX.DOI.ORG/10.6035/CLR.2012.10.4 • ISSN 1697-7750 • vOL X \2012, pp. 47-64

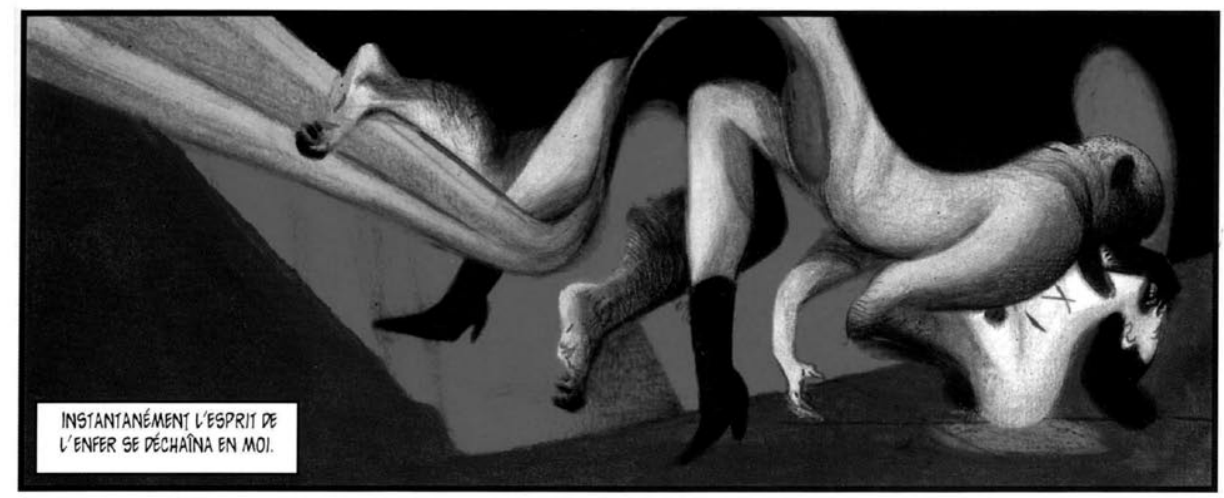

Figura 7 